Bokkos Journal of Science Report (B-JASREP) 2021; 1(2) 60-77

http://www.Jasrep.org/index.php/jasrep/index

doi: $10.47452 /$ bjasrep.v1i2.25

ISSN: $2782-7828$

\title{
Rural-Migrants Risk Tolerance in Urban City Centres of Plateau State, Nigeria
}

\author{
Joshua Yohanna, Gwanshak ${ }^{1 *}$ and Luka Dung, Gyang ${ }^{1}$ \\ ${ }^{1}$ Department of Geography, Faculty of Natural and Applied Sciences, Plateau State University Bokkos, Plateau State \\ Corresponding author: joshuayohanna1972@gmail.com
}

\begin{abstract}
This research is necessitated by identifying areas of rural migrant's risk tolerance in urban centres of Plateau State, with the stated objective of, examining the rural migrant's areas of risk tolerance, ascertain rural migrant's self-assessment capacity and competence-based towards risk tolerance. In the study, respondents were selected only if they were rural migrants using purposive sampling techniques of a sample size of 1325 respondents. Primary data were collected using a Structured Questionnaire (SRQ), Interview and Focus Group Discussion (FGD) processes. Out of 1325, 128 of the respondents were selected based on a recommendation as knowledgeable informant using snowball sampling. A linear regression analysis was used to test the significance of rural migrant's risk tolerance. The result revealed that Areas of risk tolerance identified were marital status, occupation, age, the pursuit of education, and Job opportunities are significant to rural migrants risk tolerance in the study. And migrants were flexible towards adapting to the situation, handle the problem better are willing to take higher risk to adapt to urban centre. The result furthers revealed self-assessment capacity and competence-base potential to risk tolerance in urban centres of Plateau State. Thus, appropriate recommendations were suggested.
\end{abstract}

Bokkos Journal of Science Report (B-JASREP) 2021; 1(2) 62-79

60 


\section{Keywords: Migrants, Plateau State, Risk, Risk Tolerance, Rural, Urban}

\section{Introduction}

Risk in every facet of life has gained attention in the last decades and presently is a concern to migration as one area of uncertainty that migrants experience at the cause of their movement to a new destination that could be an economical, political and environmental risk. Geographical and cultural elements may influence the risk weight of the single determinant in different continents and different periods [1]. Climate change, economic globalization, and technological developments are among the factors causing uncertainty in migration (2). Risks in migration depend on geographical location, legislation, policies, presence of risk management tools, personal and institutional risks, and disaster-related factors [3]. Risk is defined as any situation in which the outcome of one or more events is not known with certainty or not known for sure, ahead of time [4]. The risk could cause hesitation to migrants regarding the treatments that may experience, despite probable measure taken for actions to migrate. Risks of migration relate to threats to the physical integrity, wellbeing, and fundamental rights of migrants and it is defined as an uncertain event or condition that, if it occurs, can cause significant negative impact [5]. Moreover, migration decisions are rarely made without some knowledge about risks in the destination, so that an individual capability to determine risk and uncertainty is unknown. Besides, rural migrants are said to have higher risk tolerance levels in the destination of relocation [6].

Rural Migrants' risk tolerance can be the courage to apply various strategies or innovations to increase their adaptation amid uncertain situations in the future. Risk tolerance is affected by various factors, including age and education level, earnings, status, occupation and whether or climate change [7] and because the factors affecting rural' risk tolerance differ according to the location and management strategies and also the need to be migrant-specific so that applied strategies that can address the needs and motives of specific migrants. To motivate migrants to have a higher risk 
tolerance, it is important to increase awareness about the possible effects of potential risks. This can be achieved by improving their skills and knowledge, providing up-to-date information, and increasing their adaptive capacity [8]. The migrant who receives capacity-building training tends to have a positive attitude towards new technology and innovations and are more risk-tolerant.

Although there are limited researches on migration on risk tolerance, some empirical evidence is available, especially for internal migration. Several large-scale surveys on risk attitudes have established that immigrants have higher risk tolerance levels than non-migrants in the destination populations. This provides evidence that internal migrants are more risk-tolerant. Risk tolerance controls a range of socioeconomic individual characteristics, such as employment and marital status and the willingness to take risk accounts for much of the residual variance in migration intentions.

General risk researches have also found consistent differences in risk tolerance amongst socio-demographic groups. Therefore, mobility should be understood as characterized by expectations about risk formed under conditions of partial knowledge and uncertainty [9]. Risk tolerance decreases with age, but differences among individuals remain remarkably stable [10]. Men tend to be more risk-tolerant than women [11]; Younger individuals are less risk-averse than older ones [12]: More educated individuals tend to be more risktolerant [13]

\section{Statement of the Research Problem}

Few empirical studies have sought to quantify the relationship between risk tolerance and migration from a diverse perspective. However, most studies measured risk tolerance in generic terms, rather than migration specific and even though the moderate decline of risk tolerance was found in gender, age, occupation and changes over the socioeconomic characteristics may identify with people that are more likely to migrate. But neither these changes in socio-demographic and socio-economic features have significant impacts on the willingness to take a risk.

Plateau state urban centres in recent times have experienced a large influx of rural migrants to the city centres and noticeably, 
willingness to take the risk to reside or be risk tolerance is seen among them and cannot explain how only some individual migrants have the willingness to risk tolerance. According to Sahm [15], "there is 'constant relative risk tolerance' over time, while there are 'large stable differences across individuals in their risk tolerance type". The levels of explanation provided in most research on willingness to take risk are relatively low even where significant relationships are identified. This is because the areas of risk tolerance have not been identified to a large extent on rural migrants in urban centres. However, this research is necessitated to identify areas of rural migrants risk tolerance in urban centres of Plateau state.

\section{Research Objectives}

The research aimed at examining the rural migrants' areas of risk tolerance in urban centres of Plateau state with the postulated objectives as follows:

i. Ascertain rural migrants' selfassessment capacity to risk tolerance in urban centres.

ii. Evaluate the competence-based of rural migrants on risk tolerance in urban centres.
iii. Examine areas of risk tolerance as it influences rural migrants in urban centres.

\section{Relevant Literature Review}

Risks are encountered in most aspects of everyday life, ranging from the trivial to the deeply serious [9]. Migration is both informed by risk and uncertainty, and generates risk and uncertainty, whether for migrants, non-migrants in sending communities, or populations in the destination countries. Risks are to different degrees, in all forms of migration - whether as refugees, asylum-seeking, regular or irregular migration - and at all stages of the migration cycle. Risk is also scalar, and can be thought of as impacting - or being impacted on - at the individual, household, community, regional, national and global levels. migration is informed by risk: who migrates and who does not, the destinations of migrants, the channels of migration, their experiences abroad, and decisions to stay and return. There are several reasons why migrants might take a risk. First, migrants might have different perceptions or knowledge of risks. Migrants may perceive work-related risks differently because of job 
conditions. Besides, lower levels of education, social capital, and English ability may lead to migrants' having less information about job risks. These lower average levels of education could result in migrants being less able to understand risks.

Rural Migrants head towards cities based on the belief that in cities they will find better prospects in terms of income and support networks. Furthermore, large cities are generally the point of entry ("Gateway Cities") to the host country and serve as information centres [16]. Generally, people migrate to cities for economic reasons and perceived better living conditions, but they may also end up in cities as a result of civil and political unrest, war or natural disasters. In Asia, Africa and Latin America Approximately 40 per cent of urban growth is caused by internal migration from rural to urban areas.

Finding a safe and affordable place to live is an important aspect of the migrant in receiving societies. The availability, accessibility and affordability of suitable housing is a need for migrants and where migrants are at risk of greater discrimination in the housing markets; low-income migrants and ethnic minorities are likely to settle in more deprived urban areas in poor quality housing and under conditions of overcrowding, paying a higher proportion of their income for sub-standard housing to require risk tolerance [17]. The economic and employment integration of migrants is one of the challenges faced by cities. Unless they are highly skilled, migrants are more likely to be unemployed, have temporary or insecure jobs, lower-income and/or be employed in the informal sector. Migrants, particularly recent ones, therefore might hold more physically strenuous jobs. These physically strenuous jobs, which are prevalent in sectors like construction, meatpacking, and agriculture, may involve more workplace risks. Migrants work under more hazardous conditions.

\section{Rural Migrants' Risk Tolerance}

Grable [18] defines risk tolerance as "the maximum amount of uncertainty that someone is willing to accept when making a decision, which reaches into almost every part of social and economic life". Whereas, Gärling et al.[19] has contributed with another explanation for risk-taking, "risktaking is an important component of decision making. However, Cooper et al. 
[20] argue that despite the numerous studies performed on financial risk tolerance, there is a lack of cohesiveness when it comes to how to define and interpret rural-urban migration risk tolerance. Yao et al. [21] concluded in their research that risk tolerance decreases with age, which indicates that high-risk tolerance is associated with young individuals. In contrast, other authors such as Wang and Hanna [22] discovered that older individuals are more risk-tolerant than young individuals when it comes to financial decision-making. As for several of the other mentioned variables, previous authors suggest that females, regardless of marital status, are less risk-tolerant than males (Yao et al., 2011). However, risk tolerance would be influenced by the respondent's selfperception knowledge of risk. Jaeger et al [23] found that the willingness to take risks explains a significant part of the variance in migration intentions, after controlling for socioeconomic differences. Interestingly, they also discovered that risk tolerance was more effective in explaining the decision to migrate/stay, as opposed to how far to move. Some of the empirical findings of the generic research on risk tolerance are also potentially interesting to migration researchers. There is only room here to emphasize a few salient findings:

i. Women are less willing than men to take risks [24,23].

ii. Willingness to take risks decreases with age [25-26].

iii. Young adults and teenagers are more likely to be not only more risktolerant but may also be risk-seeking in their migration behaviour and intentions.

iv. More educated individuals, or those with more educated parents, are more willing to take risks [26-27]

v. Willingness to take risks varies across countries, even amongst the more developed economies.

There is a tendency for risk tolerance to change over the migration cycle. Ruralurban migration experiences modify willingness to take a risk, perhaps as a result of enhanced risk resilience or increased experience of building social networks which reduce risk levels for individuals in the external environment [28]? Arguably, successful migration experiences do provide learning experiences that do make migrants more risk-tolerant when considering further migration. It is on this note that further 
research as this intended to consider specific areas rural migrants build their risk tolerance in adapting in urban city centres.

\section{Methodology}

This research followed several procedures to select the study area, design of survey instruments, collection of primary data, analysis and evaluation of the rural migrants risk tolerance in urban city centres. Plateau State is located in the North Central Region of Nigeria and lies between latitudes 80371 $\mathrm{N}$ and $100301 \mathrm{~N}$ and longitudes $70401 \mathrm{E}$ and 80371 E. Plateau State is located in the highlands of Central Nigeria with a lot of features that attract the reasonable number of population and supported by various economic activities within the commercial symbolized by the Jos Central Market known as the "Terminus Market". As it is, Plateau State has 17 Local Government Areas namely BarkinLadi, Bassa, Bokkos, Jos East, Jos North, Jos South, Kanam, Kanke, Langtang North, Langtang South, Mangu, Mikang, Pankshin, Qu'an-Pan, Riyom, Shendam and Wase. Out of these LGAs, few have developed to urban city centres. There are 74 small towns and 16 urban areas in Plateau State having a total projected population of 2,223,954. Urban centres in Nigeria is based on population and legal or administrative criteria. Nigeria adopts a threshold population of 20,000 people as a criterion for defining an urban centre. More so, all states and local government area headquarters are historically, legally or administratively been regarded as urban centres [29-31]. 


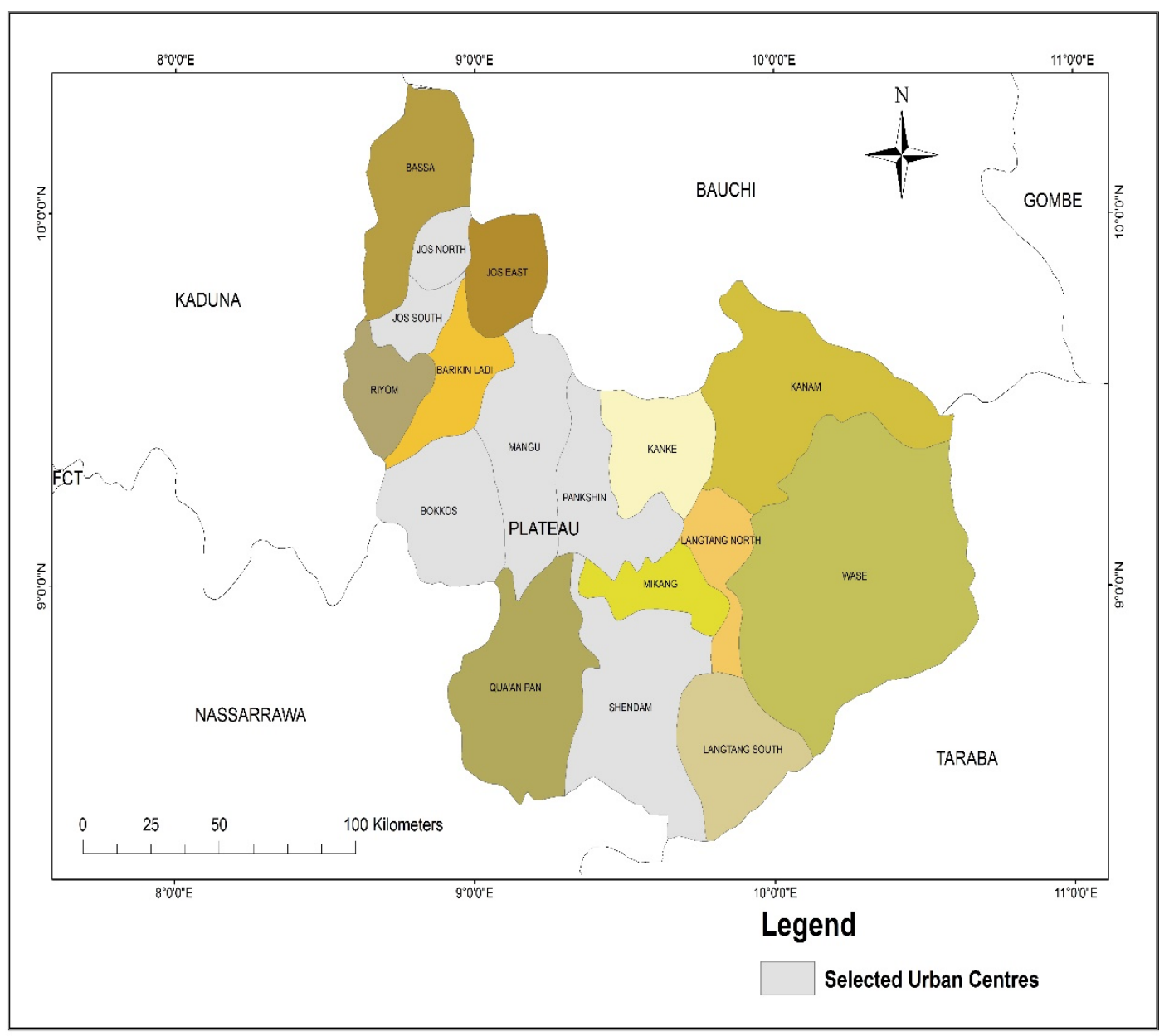

\section{Figure 1. Showing selected urban centres in Plateau State}

The study was conducted in six (6) urban city centres based on the urban population of Plateau state, which comprises of Jos-North, Jos-South, Mangu, Bokkos, Plankshan and Shendam LGAs which were the most preferred destinations of rural migrants. Because of this, respondents were selected only if they were rural migrants using purposive sampling techniques of a sample size of 1325 respondents. Primary data were collected using a Structured Research Questionnaire (SRQ), Interview and Focus Group Discussion (FGD) processes. Out of 1325,128 of the respondents were selected base on a recommendation as knowledgeable informant using snowball sampling strategy while 1197 respondents responded to the SRQ questions that were rooted in rural migrants' socio-demographic status, self-assessment capacity to risk 
tolerance, competence-based risk tolerance and areas of tolerance. After the data from the survey were collected, coding of information was done, validated and analyzed. A linear regression analysis was used to test the significance of rural migrants risk tolerance in the following:

Where; $\mathrm{Y}=* \mathrm{f} 1+\mathrm{f} 2+\mathrm{f} 3+\mathrm{f} 4+\mathrm{f} 5+\mathrm{f} 6+\mathrm{f} 7$ $+\mathrm{f} 8+\mathrm{f} 9+\mathrm{f} 10 \mathrm{uw}$

$$
\mathrm{F} 1=\text { Gender, } \mathrm{F} 2=\text { Age, } \mathrm{F} 3=
$$

Occupation, F4= Education, F5= Religion

$\mathrm{F} 6=$ Marital Status, $\mathrm{F} 7=$ self assessment capacity, $\mathrm{F} 8=$ competence - based of risk tolerance, $\mathrm{F} 9=$ areas of risk tolerance A regression model has been generated using the available variable of rural migrants in a considerable correlation at a $95 \%$ level of confidence with the notion of an obtained significant relationship. The result gotten were used to formulate the discussion of the risk tolerance in the urban city centres of plateau state

\section{Findings and Discussion}

Rural-Migrants risk tolerance is the extent to which migrant is willing to apply various innovation or strategies to remain in the urban city centre in pursuit of the reason (s) for migration. To understanding the risk tolerance migrants engage themselves; table 1 described the rural migrants' sociodemographic characteristic. $53.1 \%$ of the rural migrant's gender was male above the female 46.9\%. Age group shows, 37.1\% were between 21-30 of age that agreed with the findings of Weeks, et al, [32]; Alarima, [33] and Mutandwa et al, [34]. 81.4\% responded to be of Christians-faith which is the major religious practice in the study area. Marital status shows singles respondents were of the highest percentage with $58.7 \%$ that have the liberty to freely migrated with no much certain specific responsibilities tied to them [35]. The level of educational attainment is crucial towards risk tolerance in the urban city centre as rural migrants qualification shows $40.9 \%$ were the tertiary level of education such as NCE, diploma, HND and degree levels whereas, occupation of rural migrants revealed a high percentage of farmers with $25.1 \%$. This implies that the majority of the rural migrants to urban centres are farmers in their rural location and requires urban jobs that may demand risk tolerance. 
Table 1: Rural Migrants' Socio-Demographic Characteristics in Urban City Centres

\begin{tabular}{|c|c|c|c|c|c|c|c|c|}
\hline Descriptive & Freq & $\%$ & Descriptive & Freq & $\%$ & Descriptive & Freq & $\%$ \\
\hline Gender & & & Age & & & Religion & & \\
\hline Male & 704 & 53.1 & $11-20$ & 350 & 26.4 & Traditionalists & 38 & 2.9 \\
\hline \multirow[t]{5}{*}{ Female } & 621 & 46.9 & $21-30$ & 491 & 37.1 & Christianity & 1079 & 81.4 \\
\hline & & & $31-40$ & 273 & 20.5 & Muslim & 203 & 15.3 \\
\hline & & & $41-50$ & 119 & 9 & Others & 5 & 0.4 \\
\hline & & & $51-60$ & 58 & 4.4 & & & \\
\hline & & & $60>$ & 34 & 2.6 & & & \\
\hline Marital Status & & & Educational & Freq & $\%$ & Occupation & Freq & $\%$ \\
\hline & & & Attain & & & & & \\
\hline Single & 778 & 58.7 & Qur'anic & 100 & 7.5 & Employed & 190 & 14.3 \\
\hline Married & 445 & 33.6 & Informal & 76 & 5.7 & Entrepreneur & 230 & 17.4 \\
\hline Divorced & 45 & 3.4 & Primary & 176 & 13.3 & Farmer & 332 & 25.1 \\
\hline \multirow[t]{3}{*}{ Widow/widower } & 57 & 4.3 & Secondary & 432 & 32.6 & Unemployed & 112 & 8.5 \\
\hline & & & Tertiary & 541 & 40.9 & Students & 331 & 25 \\
\hline & & & & & & Others & 130 & 9.8 \\
\hline
\end{tabular}

\section{Researcher's fieldwork, 2020}

Rural Migrants self-assessment towards risk tolerance was considered in table 2 base on the percentage of responses to each scale questions. This, however, gave rural migrants the to respond to a scale set of questions as seen in table 2. Scale 1 revealed that $12.7 \%$ of rural migrants do not like to take a risk since they have adequate skill and capital, in as much $11.5 \%$ don't take a risk but they have skills needed to reside in urban city centres while only
$3.9 \%$ of rural migrants don't take a risk but also have capital. This implies that the rating of scale 1 shows that migrants do take a risk even when there they skills and capital to stay in urban city centres. $17.5 \%$ responded that risk-taking is possible when there is help from other people and $16.7 \%$ of rural migrants like to take a risk with common efforts while $9.6 \%$ of them take a risk with common effort on the scale 2 ratings in the study. The scale 3 indicated that $13 \%$ of the rural migrants take a risk 
with common and uncommon effort just to adapt to urban city centres and $11.6 \%$ were fully prepared to take a risk with help from others and $3.5 \%$ only prepare to take a risk with skills and capital.

\begin{tabular}{|c|c|c|}
\hline Scale & Condition & Responses \\
\hline \multirow[t]{3}{*}{1} & Do not like to take risk but have adequate skills and capital & $169(12.7 \%)$ \\
\hline & Do not like to take risk but have the skill needed & $153(11.5 \%)$ \\
\hline & Do not like to take risk but have capital & $051(3.9 \%)$ \\
\hline \multirow[t]{3}{*}{2} & Like to take risk if there is help from others & $232(17.5 \%)$ \\
\hline & Like to take risk with common efforts & $128(9.6 \%)$ \\
\hline & Like to take risk with uncommon effort & $221(16.7 \%)$ \\
\hline \multirow[t]{3}{*}{3} & Fully prepare to take risk with skill and capital & $047(3.5 \%)$ \\
\hline & Fully prepare to take risk with help from others & $154(11.6 \%)$ \\
\hline & Fully prepare to take risk with common and uncommon effort & $185(13.0 \%)$ \\
\hline
\end{tabular}

Fieldwork, 2020

Table 4 shows rural migrants' competence based on risk tolerance on staying in urban centres of Plateau state: $67.3 \%$ were more flexible when adapting to the new urban situation, $56.8 \%$ of rural migrants deaffirmed to evaluating situations correctly and takes a better decision, $70.6 \%$ of them don't handle the problem better and $59.1 \%$ have no problem with the situation they met in an urban centre while $61.5 \%$ are willing to take higher risk to adapt to urban centre. By implication, question1,3 and 5 on competence-based revealed rural migrants flexible, face challenges that might appear and are willing to take higher risk to adapt to urban centres. 


\section{Table 4. Rural Migrants' Competence-Based on Risk Tolerance in urban City Centres of Plateau State}

I am more flexible when adapting to new urban situation

I evaluate situations more correctly and take better decision

I handle problem better

I have no problem with the situation I met in urban centre

I am willing to take higher risk to adapt to urban centre
$67.3 \%($ Yes $)$
$32.7 \%(\mathrm{No})$
$43.2 \%$ (Yes)
$56.8 \%(\mathrm{No})$
$29.4 \%$ (Yes)
$70.6 \%$ ( No)
$59.1 \%$ (Yes)
$40.9 \%$ (No)
$61.5 \%($ Yes $)$

The research considered some certain areas that rural migrants will be willing to apply possible innovations or strategies to risk their stay in urban centres of Plateau state such as education, accommodations, job opportunities, financial situation and socialization base on the level of risk tolerance described in table 5. Education is one of the basic reason rural migrant moved to an urban centre and it affected the risk tolerance of migrants moderately in the sense that migrants migrate to acquire or obtain additional knowledge (education) from the institutions that are not available in rural communities. As a result of the interview conducted one of the interviewees (Bitrus Pam) stated "I left the village to secure admission at university of
Jos, so I have stay follow up for the admission and also for a teaching job in primary school to keep me busy as well get some money" many others mentioned staying with relations, become house help among others things as risk tolerance in urban centre to secure admission in institutes. Education tended to higher awareness, and the knowledge necessary to increase the strategies of adaptation with a better initiative to be more tolerant of urban challenges [33-34]. Other researchers have stated that education level is proportionally related to willingness to take risks [3] and those migrants were found to have a better understanding of risk than those with lower education levels [35]. 
Table 5 Rural Migrants Areas of Risk tolerance in urban city Centre in Plateau state. Effort made by rural-migrants when faced with certain responses based Roe (2014) were used: Likert scale values(1-4) low, (5-7) moderate and (8-10) high risk tolerance

Education risk tolerance in urban city centre

Accommodation risk tolerance in Urban city centre

Job Opportunities (Employment) in urban city centres

Financial situation in urban city centres

Socialization in urban city centres
Moderate

High

Low

High

High
Table 5 shows a regression analysis has been generated using the "independents variables" and rural migrants as 'dependent variable'. The following variables have signified considerable correlation at 0.05 level of confidence of rural migrants help to reduce the independents to the most effective and influential on the areas of risk tolerance. The variables considered were religion, marital status, education qualification, age. Self-assessment to risk tolerance, competence bases risk, the pursuit of education, accommodation tolerance, job opportunity (employment) and socialization with the notion of obtaining influencing factors to rural migrants risk tolerance in an urban centre. The regression shows a strong sign of the variables both rural migrants and areas of risk tolerance at 0.05 . And among independents variables, marital status, occupation, age, self-assessment to risk tolerance, competence-based risk, Pursuit of Education in urban centre and job Opportunity in the urban city centre were showing a position significant in relationship to rural migrants risk tolerance. This implies that rural migrants in the urban centre have the potential tolerance towards marital status. For instance, If a woman from a rural area married to a man in an urban city centre resists all challenge to stay with her husband or create strategies to remain in the relocated place. The computation shows $(\mathrm{P}>$.0.05). Significant relationship were seen at $\mathrm{f} 2(0.00), \mathrm{f} 4$ (0.039), f5(0.008), f6(0.016), f6(0.00)

Bokkos Journal of Science Report (B-JASREP) 2021; 1(2) 62-79 
$+f 7(0.00)$, $f 9(0.019)$.. However, religion, education qualification, accommodation tolerance and socialization were insignificant to rural migrants risk tolerance. By implication, rural migrants have no tolerance to the insignificant variables, migrant might choose to return to rural areas.

Table 5 RegressionCo-efficients ${ }^{\mathrm{a}}$ Rural-Migrants on areas of Risk Tolerance in Urban City Centres

\begin{tabular}{|c|c|c|c|c|c|c|c|}
\hline \multirow[b]{2}{*}{ Model } & \multicolumn{2}{|c|}{$\begin{array}{c}\text { Unstandardized } \\
\text { Coefficients }\end{array}$} & \multirow{2}{*}{$\begin{array}{c}\text { Standardized } \\
\text { Coefficients } \\
\text { Beta }\end{array}$} & \multirow[b]{2}{*}{$\mathrm{t}$} & \multirow[b]{2}{*}{ Sig. } & \multicolumn{2}{|c|}{$\begin{array}{c}95.0 \% \text { Confidence } \\
\text { Interval for B }\end{array}$} \\
\hline & B & $\begin{array}{l}\text { Std. } \\
\text { Error }\end{array}$ & & & & $\begin{array}{l}\text { Lower } \\
\text { Bound }\end{array}$ & $\begin{array}{l}\text { Upper } \\
\text { Bound }\end{array}$ \\
\hline (Constant) & 1.186 & .120 & & 9.878 & .000 & .950 & 1.421 \\
\hline Reliigion & -.030 & .032 & -.027 & -.926 & .354 & -.094 & .034 \\
\hline Marital Status & .189 & .023 & .265 & 8.169 & .000 & .143 & .234 \\
\hline Level of Education & -.013 & .011 & -.035 & -1.172 & .242 & -.035 & .009 \\
\hline Occupation & -.015 & .007 & -.060 & -2.064 & .039 & -.030 & -.001 \\
\hline Age & -.034 & .013 & -.087 & -2.677 & .008 & -.060 & -.009 \\
\hline Self-Assessment to risk tolerance & .045 & .019 & .073 & 2.421 & .016 & .009 & .082 \\
\hline Competence Based Risk & -.043 & .011 & -.114 & -3.823 & .000 & -.065 & -.021 \\
\hline Pursuit of Education in urban centre & .077 & .020 & .114 & 3.936 & .000 & .039 & .115 \\
\hline Accommodationtolerance in urban centre & -.061 & .079 & -.092 & -.781 & .435 & -.216 & .093 \\
\hline Job Opportunity in Urban city centre & .061 & .026 & .095 & 2.353 & .019 & .010 & .113 \\
\hline Socialization & -.015 & .086 & -.023 & -.176 & .860 & -.183 & .153 \\
\hline
\end{tabular}

a. Dependent Variable: Rural Migrants

\section{Conclusion}

The study on rural migrants' risk tolerance in urban city centres of Plateau state has been explicit on the areas of risk tolerance migrants resist threats to the physical integrity, wellbeing and fundamental rights of their staying in urban centres. This became necessary for migrants to apply strategies or innovations that enable them to have higher risk tolerance in destination relocated as stated by Williams and Balaz, [6]. However, the findings have shed light on the socio-demography features of the 
rural migrants with a higher percentage representation of youthful single age population that are Christian dominated with a tertiary level of education as well larger numbers of farmers as their occupation. It is indicated that rural migrants' self-assessment to risk tolerance shows effort to take a risk with help from others and are fully prepared to take a risk with common and uncommon effort. This effort made rural migrants expressed their competence base through being flexible when adapting to the new urban situation, chooses to handle uncertainty issues better and were willing of taking the higher risk to reside in urban centres. The willingness to take risk accounts for much of the residual variance in rural-urban migration intentions that the study has identified as areas of risk tolerance of rural migrants which includes; marital status, occupation, age, self-assessment capacity, competence-base potential, the pursuit of education and job opportunities (employment). These areas have made rural migrants creating innovations or strategies to tolerate any threat of hindrance to the reasons for their relocation to the environment. Most importantly, rural migrants are risk-tolerant in urban city centres of Plateau state.
Policy Implication: the findings of the study addresses rural migrants risk tolerance in urban centres of Plateau state which contribute in knowing the behaviour of migrants in relocated environment that pull them out of their original location. This has brought out the disregarded areas in migration study that needed a critical examination in solving rural-urban migration issues. The study on migration risk tolerance could further investigate tolerance in gender perspective among migrants in the region and the implications of migrants risk tolerance to the environment

Funding: This research has not received any sort of external funding

\section{Conflict of Interest}

There is no conflict of interest in this research from the actors

\section{REFERENCES}

1. Castelli. Drivers of migration: why do people move? Journal of Travel 
Medicine, 2018, "'1-7. DOI:

10.1093/job/tay040

2. Jianjun, Jin, Yiwei, Gao, Xiaomin, Wang, Nam, Pham Khanh, 2015.

Farmers' risk preferences and their climate change adaptation strategies in the Hongqiao district, China. Land Use Policy 47, 365-372

3. Ullah, Raza, Shivakoti, Ganesh P., Kamran, Asif, Zulfiqar, Farhad.

Farmers versusnature: managing disaster risks at the farm level. Nat.

Hazards, 2016, 82, 1931-1945

4. Chavas. Risk Analysis in Theory and Practice. Academic Press, 2004.

5. World Economic Forum. The Global Risk Report. Available at: http://reports. weforum.org/ The Global Risk Report /. 2021.

6 Williams, A. M. \&Baláž, V.

Migration, risk and uncertainty:

theoretical perspectives.

Population Space and Place, 2012, 18, 67-80.

7 Ullah, Raza, Shivakoti, Ganesh P., Ali, Ghaffar. Factors affecting farmers' risk attitude and risk perceptions: THE case of KhyberPakhtunkhwa, Pakistan. Int.
J. Disast. $\quad$ Risk Reduce. 2015, 13, 151-157.

8. Zeweld, Woldegebrial, Van Huylenbroeck, Guido, Tesfay, Girmay, Speelman, Stijn. Impacts of socio-psychological factors on smallholder farmers' risk attitudes: empirical evidence and implications. Agrekon 2019, 58 (2), 253-279.

9. Balaz\&Valus. Migration, risk tolerance and life satisfaction: evidence from a large scale survey: Journal of Risk Research, DOI:

10.1080/13669877.2020.1750454.

10. Donkers, B., Melenberg, B. \& van Soest, A. Estimating risk attitudes using lotteries: a large sample approach. Journal of Risk and Uncertainty, 2001, 22: 165-195.

11. van Dalen, H. P. \&Henkens. Explaining low international labour mobility: the role of networks, personality, and perceived labour market opportunities. Population Space and Place, 2012, 18, 31-44.

12. Hemelt, S. W. and Stange, K. M. "Why the move to online instruction 
won't reduce college

costs".Brookings Institution. 28 July 2020.

https://www.brookings.edu/blog/bro

wn-center-

chalkboard/2020/07/28/why-themove-to-online-instruction-wontreduce-college-costs/

13. Hallahan, T. A., Faff, R. W. \& McKenzie, M. D. An empirical investigation ofpersonal financial risk tolerance. Financial Services Review, 2004, 13, 57-78.

14. Sahm, C. R. "How Much Does Risk Tolerance Change?" Quarterly

Journal of Finance 2012, 2 (4): 1250020. DOI:

10.1142/S2010139212500206.

15. UN-Habitat. The State of African Cities: Re-imagining sustainable urban transitions. United Nations Human Settlements Programme (UN-HABITAT). Nairobi, Kenya. 2014.

16. Bosswick, W., Fassman, H., Kohlbacher, J.\& Luken-Klassen, D. Housing and residential segregation of migrants: a state-ofthe-art report.Institute for Urban and
Regional Research, Te Austrian Academy of Sciences, Vienna. 2007.

17. Grable, J.E. (2000). Financial Risk Tolerance and Additional Factors That Affect Risk Taking in Everyday Money Matters. Journal of Business and Psychology, 2000, 14, 625-630.

18. Gärling, T., Kirchler, E., Lewis, A., \& van Raaij, F. Psychology, Financial Decision Making, and Financial Crises. Psychological Science in the Public Interest, 2009, 10(1), 1-47. DOI:

$10.1177 / 1529100610378437$

19. Cooper, W.W., Kingyens, A.T., \&Paradi, J.C. Two-stage financial risktolerance assessment using data envelopment analysis. European Journal of Operational Research, 2014, 233, 273-280. DOI: 10.1016/j.ejor.2013.08.030

20. Yao, R., Sharpe, D.L., \& Wang, F. Decomposing the age effect on risk tolerance. The Journal of SocioEconomics, 2011, 40, 879-887.DOI: 10.1016/j.socec.2011.08.023.

21. Wang, H. \& Hanna, S. Does Risk Tolerance Decrease with Age? 
FinancialCounseling and Planning, 1997, Volume 8(2), 27-32.

22. Jaeger, D.A., H. Bonin, A. Falk, D. Huffman, T. Dohmen, and U. Sunde. Direct Evidence on Risk Attitudes and Migration. Discussion Paper No. 265, Berlin: Institute for the Study of Labour.2007.

23. Hartog, J., Ferrer-i-Carbonell, A. \&Jonker, N. On a simple measure of individual risk aversion. Munich: CESifo Working Paper Series No. 363, Center for Economic Studies and Ifo Institute for Economic Research. 2000

24. Donkers B, Melenberg B, Soest A.

Estimating risk attitudes using

lotteries: a

large sample approach. Tilburg

University, Tilburg Center for

Economic Research

Discussion Paper 9912:

TilburgDonkers et al 1999

25. Dohmen T, Falk A, Huffman D, Sunde U, Schupp J, Wagner G.

Individual Risk

Attitudes: New Evidence from a

Large, Representative, Experimentally-Validated
Survey. Institute for the Study of Labour, IZA Discussion Paper 1730: 2005.

26. Dohmen, T. J., A. Falk, D. Huffman, J. Schupp, U. Sunde, and G. G.

Wagner. $\quad$ "Individual Risk Attitudes: NewEvidence from Large, Representative, ExperimentallyValidated Survey." CEPR

Discussion Paper No. 5517. London: Centre for Economic Policy Research. 2006.

27. Brunnermeier Markus K. \& Stefan Nagel. "Do Wealth Fluctuations Generate TimeVarying Risk Aversion? Micro-evidence on Individuals," American Economic Review, American Economic Association, 2008, vol. 98(3), pages 713-36, June

28 National Urban Development Policy, 2006

29. Weeks, J., Davis, J. \& Lopez-Carr, D. Migration, Remittances, and Cattle: Implications for Land Use Change and Food Security in Central America:Papers of the Global Land Project Open Science 
Meeting., Central America: Arizona

State University Press. 2010

30. Alarima, C.I. Factors influencing

rural-urban migration of youths in

osun state, nigeria. Agro-Science

Journal of Tropical Agriculture,

Food, Environment and Extension,

2018, 17 (3), 34-39. ISSN 1119 -

7455 .

31. Mutandwa E., Kanuma-Taremwa N., Uwimana P., Gakwandi, C. and Mugisha F. An analysis of the determinants of rural to urban migraton among rural youths in northern and western provinces of Rwanda. Rwanda Journal, 2011, 22 (B), 55-95.

32. Ajaero, C. K. and Onokala, P. C. "Spatial appraisal of socioeconomic impacts of Rural out-migration in the Niger Delta region," in Proceedings of the TTI and CPEDWorkshop on Confronting the Challenges of Development, Environmental Management and Peace Building in the Niger Delta: Beyond the Amnesty, 2011, pp. 23-34, Benin, Nigeria, July 2011.
33. Gracia-Pabon, Jose L. Risk concern among Latino farmers in Missouri: An Approximation. Culture Agric. Food and Envirob. 2011, 33 (11). 15-29

34. Miyata, Sachiko. Household' s risk attitudes in Indonesian villages household' $s$ risk attitudes in Indonesian villages. Appl. Econ. 2010, 35 (5), 573-583

35. Asravor, Richard. Smallholder farmers' risk perceptions and risk management responses: evidence from the SemiArid region of Ghana. Afr. J.

Econom. Manag.

Stud. 2018, 9 (3), 367-387. 